\title{
Investigation of the Kinetics of the Drying Process of Composite Pellets on a Convective Drying Stand
}

\author{
Zhanna Petrova ${ }^{1 *}$, Yurii Sniezhkin'1, Vadym Paziuk' Yuliia Novikova', Anton Petrov ${ }^{1}$ \\ 1 Department of Heat and mass transfer in heat technologies, Institute of Engineering Thermophysics of NAS \\ of Ukraine, 2a, Marii Kapnist Str., 03057, Kyiv, Ukraine \\ * Corresponding author's email: bergelzhanna@ukr.net
}

\begin{abstract}
In Ukraine, the problem of processing and utilization of sludge deposits that are formed during the treatment process at wastewater treatment plants is relevant. Unprocessed sewage sludge merges into overcrowded sludge sites every year, which leads to a deterioration of the environment and living conditions in Ukraine. Therefore, the aim of the work was to study the processing of sludge, the creation of pellets based on their composition with peat and biomass and their drying. The article presents the studies of drying kinetics of composite pellets based on peat, obsolete sludge and biomass on an experimental convective drying stand. The influence of the proportions of the components of the composition on the drying time was determined and the ratio at which the drying time of the pellets is shorter and the pellets are of better quality was selected. A comparison of the drying time of the sludgepeat composition and its components was performed, which shows that during the drying of the composite pellets, the intensification of the drying process is observed. The study related to the effect of the diameter of the pellets on the duration of drying showed that the duration of drying increases along with diameter. The presented comparison of drying kinetics of two- and three-component pellets shows the same nature of the drying curves and the drying time is in the range of 17-18 minutes. The optimal ratio of components for quality granulation was selected. The effective drying regimes of composite pellets based on silt deposits, peat and biomass were determined.
\end{abstract}

Keywords: obsolete sludge, peat, biomass, granulation, drying, pellets.

\section{INTRODUCTION}

Preservation of natural resources and the environment from the pollution caused by human action is an urgent task at the current level of development of society. The need to preserve and increase the capacity of systems for the return and reuse of water and land resources, the development of waste-free and resource-saving technologies.

The processes of nature self-purification are very slow due to the high concentration of xenobiotics and their high resistance to decomposition. Therefore, the urgent environmental task is to restore the environment through rational processing of industrial and agricultural waste, restoring land fertility from toxic chemicals, disposal of sludge from wastewater treatment plants, treatment of water sources, etc. Among the environmental problems of modern civilization is the disposal of production and consumption waste, which is associated with waste sewage treatment plants.

Disposal of sewage waste is also associated with large volumes of sludge processing (for Ukraine it is necessary to process more than 1.8 million tons/year [Nezdoyminov \& Chernyisheva, 2012]), which accumulates over the years on sludge sites and poses an environmental hazard in the areas of storage or developed "sludge maps" located near settlements. Sludge is strictly prohibited to store without special permits and conditions; moreover, it cannot be buried in conventional landfills. The requirements for sludge sites are regulated by the State standards of Ukraine DSTU 8727:2017.

In Ukraine, in most cases, the areas where sludge are stored are overflowing and additional areas of more than 120 ha/year are needed 
[Suchkova, 2007]. These areas no longer cope with continuous sludge flows. Sludge has not been removed in Kyiv for more than 25 years, in Smila for more than 30 years, and in Kherson for 25 years. The sludge that has been stored for years needs to be recycled and is called "obsolete", containing almost no organic impurities, which complicates the process of its processing.

The problem of sludge disposal is not completely solved. Previously, it was allowed to use sludge as organic fertilizers due to the high concentration of phosphorus and nitrogen, but at the same time it is a source of pollution, as it contains a very high content of heavy metals and cannot be used in agriculture.

The chemical pollution of water has reached particularly dangerous proportions, and the struggle for the purity of the hydrosphere is becoming increasingly difficult, requiring not only huge costs, but also fundamentally new solutions. After all, the classical biological methods of wastewater treatment proposed the 19th and early 20th century are not designed to free water from xenobiotics, which did not exist at all in those distant times, and which cannot be removed using traditional biofilm and activated sludge [Hvozdiak, 2019].

In order to solve this problem, the burning of sludge has become more widespread in recent times. This process also makes it possible to obtain a positive energy balance and effectively use the calorific value of sludge [VermiTehnologii].

Therefore, it is most expedient to solve the technological problem of sludge processing through the development of fuel pellets. In the production of biofuels, the drying process is most energy-intensive. About $90 \%$ of thermal energy is spent on moisture evaporation. On average, this process consumes $12-20 \%$ of the target biofuel product produced at the enterprise. The share of electrical costs for the production needs in the overall energy balance does not change significantly. The analysis of solid biofuel production shows that the minimum level of profitability of production should be in the range from 3 to 6 , which corresponds to the moisture content of raw materials and on average not less than 55\%. The specific energy consumption for drying raw materials per ton of final product decreases along with the initial moisture content of raw materials and varies within $10 \%$, depending on the choice of drying equipment. At the initial humidity of biomass above $55 \%$, the technology of its processing passes to the category of waste utilization. The specified technical solution can be applied on condition of processing of raw materials with humidity above $55 \%$. At the same time, the combination of stages of drying and grinding in one device, or alternation (on the principle: grinding-drying of raw materials; final grinding-drying) will intensify the dehydration process and solve the problems of grinding too wet raw materials that exist in most industries [Sniezhkin et al., 2014].

Sewage sludge is disposed of through landfills, dumping in the oceans (sea), incineration and use in agriculture [Kelessidis \& Stasinakis, 2012, Matsumiya, 2014, Mininni et al., 2014, Zhen et al., 2017]. In addition to the classic methods of disposal, new methods are used globally. In the European countries, aerobic and anaerobic treatment of sewage sludge is preferred. Studies have shown that during these transformations in sludge, components of organo-mineral fertilizers are formed [Du \& Li, 2017, Kelessidis \& Stasinakis, 2012]. In Japan, the disposal of sludge is preferred: incineration, gasification, drying and carbonization [Matsumiya, 2014]. At the same time, sludge deposits are a valuable source of fertilizer components for them and for the creation of sorbents, for wastewater treatment from heavy metal ions [Tyagi \& Lo, 2013]. This is only part of the technology, but they are all designed for activated sludge, which has a high content of organic matter. In Ukraine, there is a problem of "obsolete" sludge, which is stored for years and has almost no organic matter, complicating the processing process.

\section{MATERIALS AND METHODS}

The obsolete sludge from Fastiv, the peat from the Chernihiv region and biomass, such as buckwheat husk and sawdust, were used to create the pellets. Figure 1 shows that the ash content of sludge is $47.3 \%$, which is unacceptable at burning. The peat from the Chernihiv region has a fairly low ash content of $14.1 \%$. When combining these materials, the ash content of the composition is $33.1 \%$. The biomass ash content was as follows: sawdust $-3.1 \%$, and buckwheat husks $1.6 \%$. In order to improve the quality and reduce the ash content of sludge-peat pellets, it is advisable to add sawdust and buckwheat husk. The ash content of three-component compositions is $25 \%$ [Petrova \& Novikova, 2021]. 


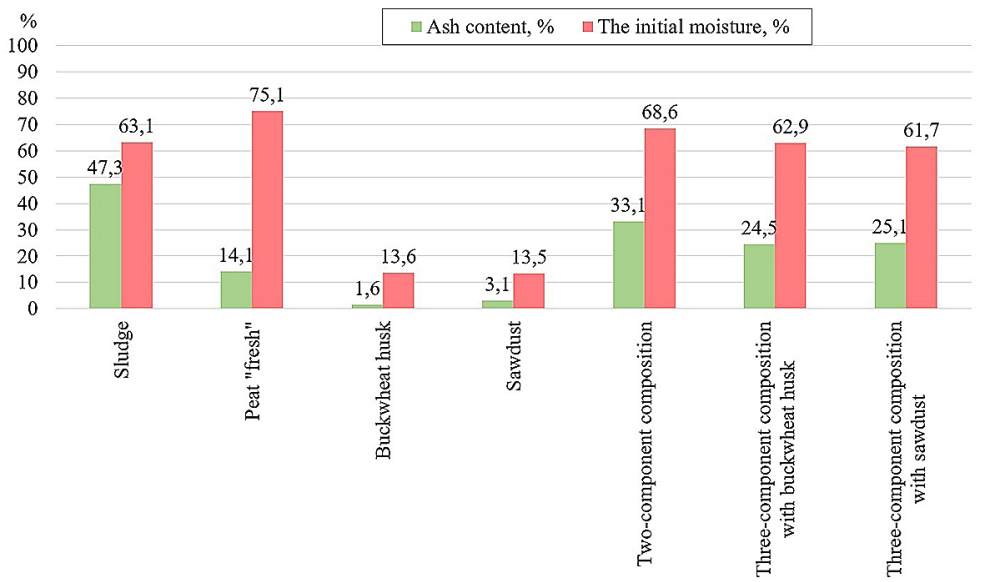

Figure 1. Technological characteristics of raw materials

Different combinations of sludge $(S)$, peat $(P)$ and biomass were selected for the production of pellets: $70 \% \mathrm{~S}+30 \% \mathrm{P} ; 50 \% \mathrm{~S}+50 \% \mathrm{P} ; 30 \% \mathrm{~S}$ $+70 \% \mathrm{P}, 45 \% \mathrm{~S}+45 \% \mathrm{P}+10 \%$ buckwheat husk; $45 \% \mathrm{~S}+45 \% \mathrm{P}+10 \%$ sawdust. The created twoand three-component combinations were subjected to granulation in a hydraulic press HLR - 12 [Petrova \& Novikova, 2021].

In order to study the kinetics of the drying process of sludge-peat pellets, an experimental convective stand with an installed automatic system of information collection and processing was used (Fig. 2) [Petrova \& Slobodyanyuk, 2019].

The experimental convective drying stand consists of the following main parts: drying chamber (1), electric heater unit (2), fan (3), insulated air ducts and drying process control systems.

The change in the wide range of the coolant speed and its temperature is achieved by regulating the operation of the fan (3) on the control panel of the speed controller (5). The speed of the coolant is changed by altering the air supply by a centrifugal fan using a frequency converter when adjusting manually. The ratio between exhaust and fresh air can be adjusted using the gates on the branch pipes (7).

After setting the test mode on the stand, a sample of the test material was placed on the rod of the scales (10) in the drying chamber, and the decrease in sample weight during drying was continuously recorded with the AD-500 scales (11) connected to the computer.

The convective drying stand allows carrying out heat treatment of sludge-peat pellets at a temperature of drying agent of $30-150^{\circ} \mathrm{C}$ and movement speed of $0.5-5 \mathrm{~m} / \mathrm{s}$. The installed highprecision scales allow registering changes of weight of a sample to $0.001 \mathrm{~g}$ and to maintaining

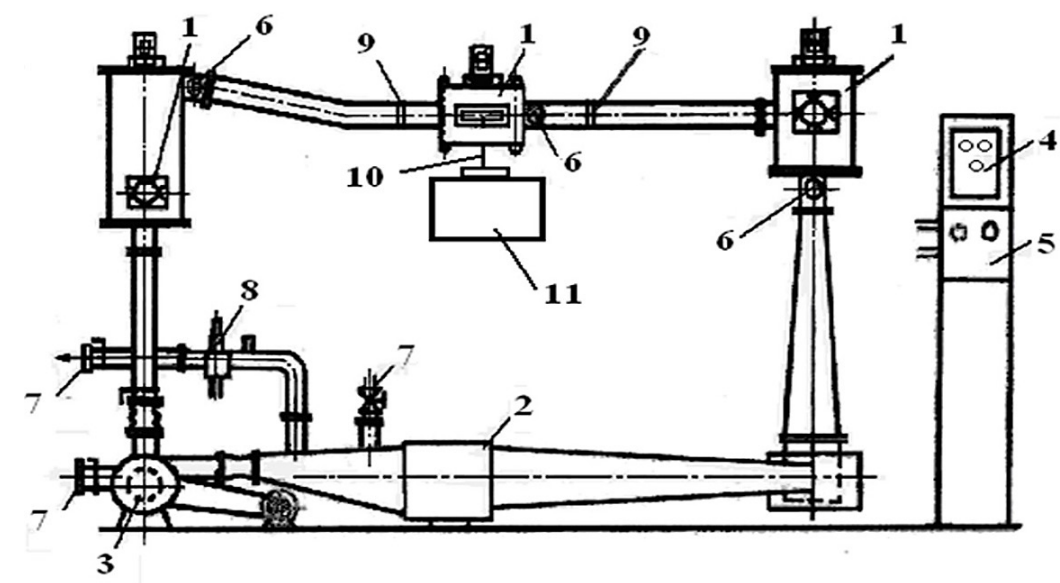

Figure 2. Scheme of the experimental convective stand for drying of composite pellets: 1 - drying chamber; 2 - electric heaters; 3 - fan; 4 - temperature regulator; 5 - speed regulator; 6 - resistance thermometers;

7 - branch pipes with gates; 8 - psychrometer; 9 - special lattices; 10 - a rod of scales; 11 - scales 
temperature in the drying chamber with accuracy of $0.02^{\circ} \mathrm{C}$. The experimental data on the change in mass and temperature of the sample, as well as the temperature of the drying agent in the drying chamber are read 7 times per minute.

In order to increase the accuracy, information and ease of processing, the information obtained during the experiments, the experimental stand is equipped with auxiliary equipment: analogto-digital converter i-7018, converter-interface i-7520 and personal computer with CPU AMD ATHLON XP 2200+ (Fig. 3). Figure 4 shows the scales with the bar with the material mounted on them. Chromel-kopel thermoelectric converters (DSTU EN 60584-1:2016) with a diameter of $0.2 \mathrm{~mm}$ were installed in the pellets.

The drying chamber is a rectangular box made of sheet iron with a removable hatch. The chamber has a clear glass, through which one can monitor the condition of the material during drying. In order to determine the change in weight during drying by weight, a rod with a grid was installed, on which the sludge-peat pellets that are subjected to heat treatment were placed (Fig. 4 a, b). Methods of research on a convective drying stand:

1. Sludge-peat pellets were chosen as the object of research.

2. Before carrying out the studies, the initial moisture of sludge-peat pellets was defined. The pellets were poured into the weighing bottles and dried in a drying cabinet for 5 hours at a temperature of $105^{\circ} \mathrm{C}$. After drying, the weighing bottles are removed from the drying cabinet and placed in a desiccator to cool for $15-30$ minutes. Chilled weighing bottles with pellets were weighed in a closed state on scales.
The humidity of the pellets relative to the mass of dry matter was calculated as a percentage:

$$
W=\frac{m_{1}-m_{3}}{m_{3}-m_{1}} \cdot 100 \%
$$

where: $m_{1}-$ weight of empty weighing bottles (with lid), g;

$m_{2}$ - mass of weighing bottles with a sample before drying, $g$;

$m_{3}$ - mass of weighing bottles with a sample after drying, $g$.

3. Studies of drying of sludge-peat pellets begin with the establishment of the drying mode on the stand, placed on the scales in the drying chamber and turn on a computer program for collecting and processing the information that continuously records the time and change of sample weight, coolant temperature and temperature in the middle of the pellets.

4. The characteristics were calculated using a specially designed "Sooshka" program.

4.1. Kinetics of the drying process.

$$
W(t)=\frac{G(t)-G_{a . d .}}{G_{a . d .}} \cdot 100 \%
$$

where: $G(t)$ - calculations of the mass of the sample, g;

$G_{\text {a.d. }}$ - absolutely dry mass of material, $\mathrm{g}$.

4.2. The drying rate is determined using the formula:

$$
N=\frac{d W}{d \tau}
$$

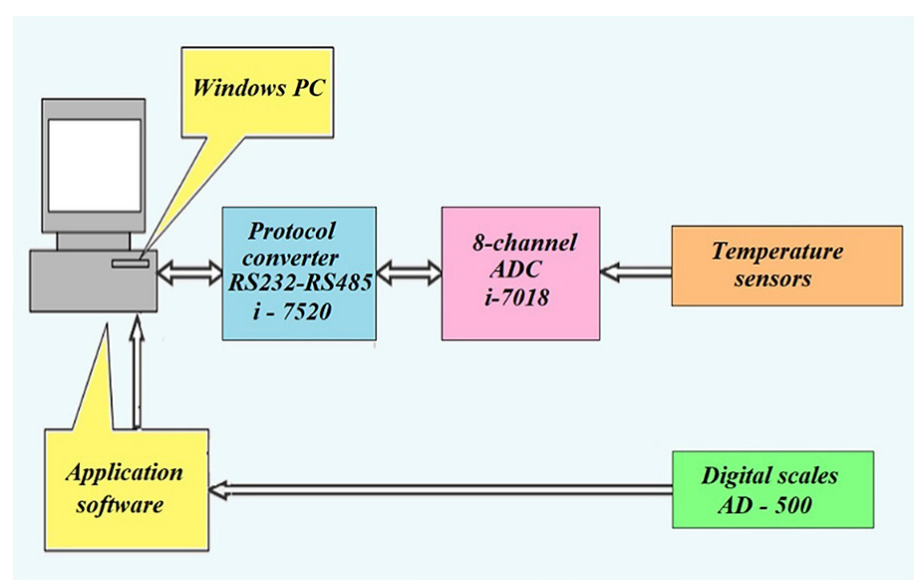

Figure 3. Block diagram of automated collection and processing of information from the convective drying stand 


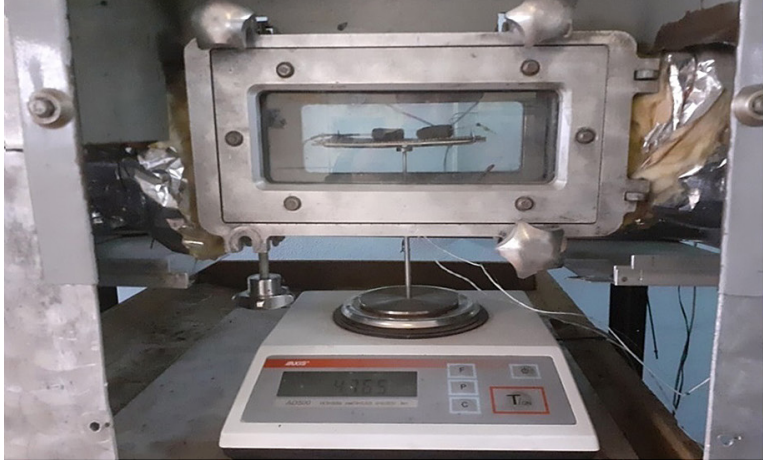

$\mathbf{a}$

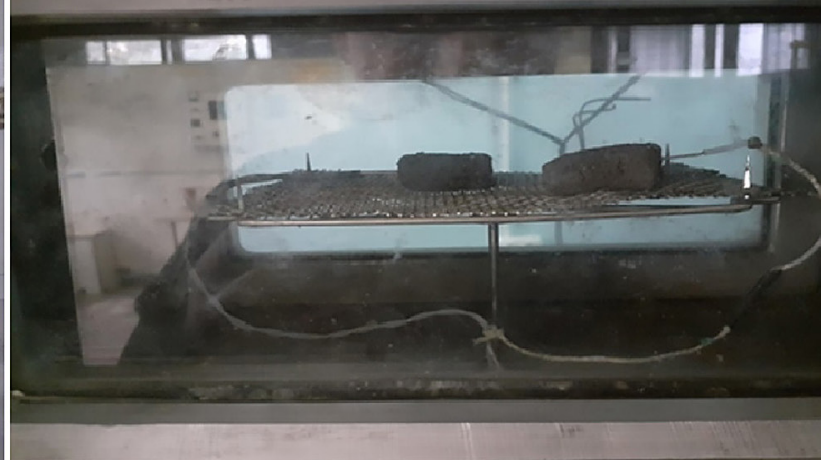

b

Figure 4. Installation for drying of sludge-peat pellets: a - the general type of scales with the established pellets in the drying chamber; $b$-drying chamber during drying of pellets

4.3. The temperature coefficient of drying is an estimate of the derivative of the average temperature of the sample from the moisture content:

$$
b=d t_{a v} / d U
$$

where: $U=W / 100$ - moisture content of the sample, $\%$;

$t_{a v}$-is calculated as the average value of the calculation of the temperature on the surface and in the sample material, ${ }^{\circ} \mathrm{C}$.

\section{RESULTS}

The granulation study showed that strong pellets were obtained at a ratio of $50 \% \mathrm{~S}+50 \% \mathrm{P}$ and $45 \% \mathrm{~S}+45 \% \mathrm{P}+10 \%$ biomass. Further studies were performed on these compositions.

Temperature curves were first introduced by A.V. Lykovym and important for the analysis of the drying process. In the initial stage, the heating

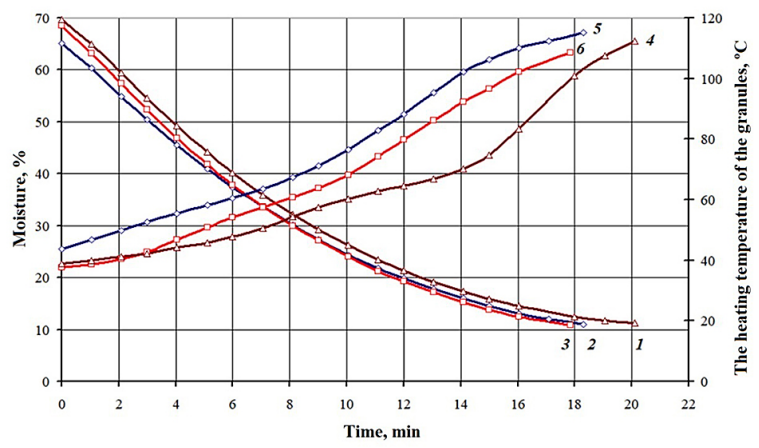

Figure 5. The effect of the proportion of sludge-peat composition on the drying time of the pellets at $\mathrm{t}=$ $120^{\circ} \mathrm{C}, \mathrm{V}=2 \mathrm{~m} / \mathrm{s}, \mathrm{d}=6 \mathrm{~mm}: 1,4-70 \% \mathrm{~S}+30 \%$ $\mathrm{P} ; 2,5-30 \% \mathrm{~S}+70 \% \mathrm{P} ; 3,6-50 \% \mathrm{~S}+50 \% \mathrm{P}$ of the surface of the material is intense, quickly reaching the temperature of the wet bulb thermometer. Drying curves characterize the change in average humidity of the material $W^{c}$ over time. The analysis of these drying curves shows that at the beginning of the process, when the humidity of the material decreases intensively along the curve, there is a short stage of heating the material, then the humidity changes in a straight line, this first period is called the first drying period.

Fig. 5 shows the temperature curves and drying kinetics of sludge-peat pellets on a convective drying stand at a temperature of $120^{\circ} \mathrm{C}$ in different proportions: $70 \% \mathrm{~S}+30 \% \mathrm{P} ; 50 \% \mathrm{~S}+50 \% \mathrm{P}$; $30 \% \mathrm{~S}+70 \% \mathrm{P}$.

The study of the effect of the composition showed that the shortest drying time of the pellets in the composition is $50 \% \mathrm{~S}+50 \% \mathrm{P}$ (curve 3 ). An increase in the sludge ratio leads to an increase in the drying time of the pellets (curve 1), but a decrease in the sludge ratio does not always reduce the drying time (curve 2 ).

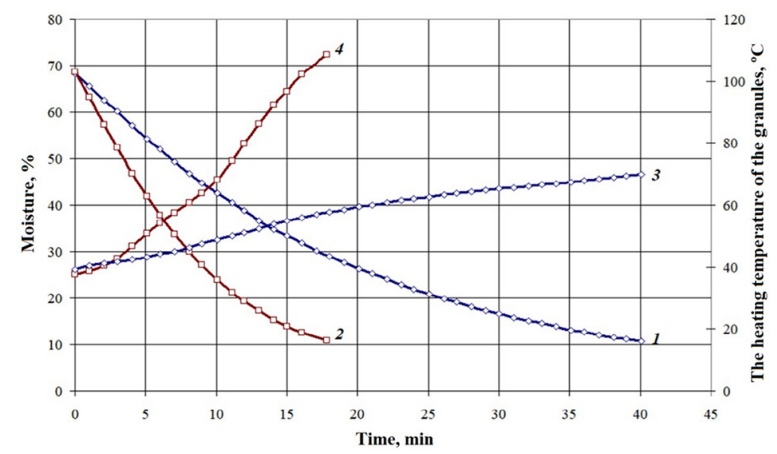

Figure 6. The influence of the size of the pellets on the duration of drying at $t=$ $120^{\circ} \mathrm{C}, V=2 \mathrm{~m} / \mathrm{s}$, the ratio of $50 \% \mathrm{~S}+$ $50 \% \mathrm{P}: 1-d=6 \mathrm{~mm} ; 2-d=12 \mathrm{~mm}$ 
The nature of the drying of the pellets from the composition of $70 \% \mathrm{~S}+30 \% \mathrm{P}$ differs from others (curve 4), up to $12 \mathrm{~min}$ there is a slow heating, followed by a sharp heating to the final temperature. The strongest pellets were obtained after drying in the proportion of $50 \% \mathrm{~S}+50 \% \mathrm{P}$ and achieved the shortest drying time.

Figure 6 shows the temperature curves and drying kinetics of the composition $50 \% \mathrm{~S}+50 \%$ $\mathrm{P}$ depending on the diameter of the pellets. As can be seen from the temperature curves, the heating is more intense in the pellets with a diameter of $6 \mathrm{~mm}$. The studies of the effect of the diameter of the pellets have shown that with increasing diameter of the pellets, the drying time increases by 2.2 times.

Figure 7 shows the samples of pellets with a diameter of 6 and $12 \mathrm{~mm}$ after drying at a coolant temperature of $120^{\circ} \mathrm{C}$. As can be seen from the figure, the pellets with a diameter of $6 \mathrm{~mm}$ have a uniform shape and are stronger.

Figure 8 shows the temperature curves and kinetics of drying of peat, sludge and their composition. For 30 minutes, the peat is heated to a drying temperature of $120^{\circ} \mathrm{C}$. The sludge reaches this temperature within 20 minutes, and their composition has the character of heating sludge and reaches a given temperature after 20 minutes. The drying kinetics of peat, sludge and composite pellets were compared. As can be seen from the figure, in all the presented curves, this period is short. Basically, there is a second drying period, which is characterized by a decrease in the intensity of moisture.
The sludge-peat composition at a coolant temperature of $120^{\circ} \mathrm{C}$ to final moisture of $10 \%$ is dried for 24 minutes, which is $12 \%$ more than sludge and 2.3 less than peat. The heating temperature of the material in the sludge is $109.1^{\circ} \mathrm{C}$, peat $-119.6^{\circ} \mathrm{C}$, in the sludge-peat composition $-115.2^{\circ} \mathrm{C}$.

In order to reduce the ash content of the pellets, a three-component composition based on sludge-peat was created, to which $10 \%$ sawdust or $10 \%$ buckwheat husk was added. The creation of three-component pellets took place on a hydraulic press.

Figure 9 shows the temperature curves and drying kinetics of two- and three-component pellets. As can be seen from Figure 9, the drying kinetics of the pellets of the three-component compositions are similar and the curves overlap (curve 2,3). The drying kinetics curves of the two- and three-component compositions show that the drying proceeds with a gradual decrease in humidity. The drying time of the pellets for both two- and three-component compositions is in the range of 17 to 18 minutes.

Temperature curves have different character. The three-component pellets with sawdust up to $16 \mathrm{~min}$ are heated intensively to a uniform temperature (curve 6), but the pellets with buckwheat husk up to $14 \mathrm{~min}$ are heated slowly, and then there is a sharp increase to the final value (curve 5).

The comparison of the formed three-component pellets with two-component ones showed the same nature of the drying curves. The duration of drying of three-component pellets at a coolant temperature of $120^{\circ} \mathrm{C}$ to a final humidity of $10 \%$ is $17-18$ minutes.

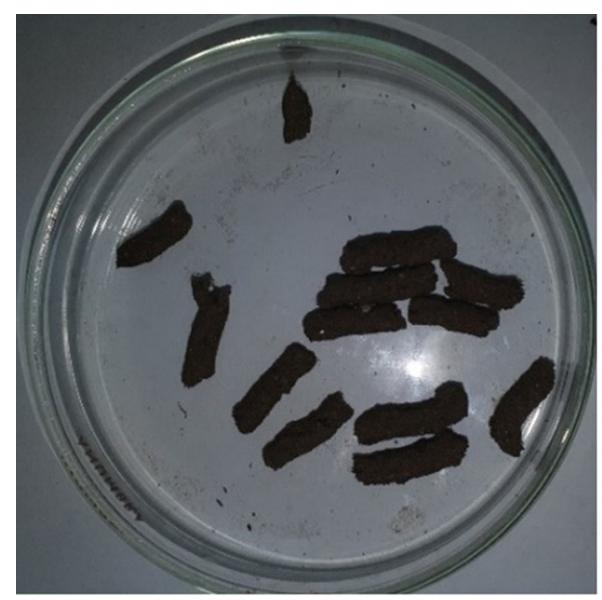

a

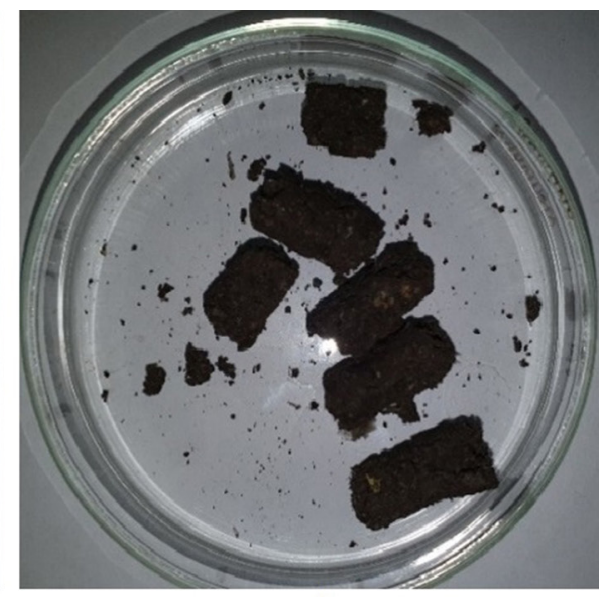

b

Figure 7. Samples of pellets with after drying at a temperature of $120^{\circ} \mathrm{C}$ : a - diameter of $6 \mathrm{~mm}$; b - diameter of $12 \mathrm{~mm}$ 


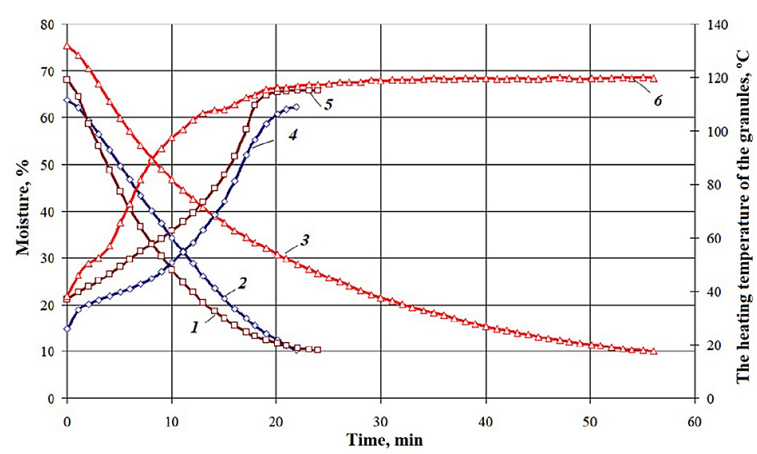

Figure 8. Comparison of the drying time of the sludge-peat composition and its components at $\mathrm{t}=120^{\circ} \mathrm{C}, \mathrm{V}=2 \mathrm{~m} / \mathrm{s}, \mathrm{d}=6 \mathrm{~mm}: 1,5$ - sludgepeat composition; 2,4 - sludge; 3,6 - peat

Elimination of accumulated sludge is required for efficient and uninterrupted operation of treatment facilities. Therefore, it is important to develop a technology for processing sludge into fuel pellets with a simultaneous production of heat and electricity.

\section{CONCLUSIONS}

1. The results of experimental research obtained in the work to determine the technological characteristics are only one of the stages of the experiments. As a result of these experiments, the optimal ratio of components with better quality characteristics than sludge was selected. Peat addition can reduce the ash content in sludge by 1.4 times with the subsequent addition of biomass by 1.9 times.

2. The study of the influence of the ratio of components shows that the shortest drying time in the proportion of $50 \mathrm{~S}+50 \mathrm{P}$. This ratio is optimal, has the best quality characteristics and is selected for further research. The size of the granules also affects the drying process; the duration of drying increases along with increasing and heating is not so intense.

3. The comparison of drying kinetics of peat, sludge and their composition showed that the drying process is more intensive and has the same drying character as sludge. The obtained drying kinetics curves have the same character in two- and three-component granules, but the temperature curves have different character.

4. The optimal ratio of components was selected for the purpose of high-quality granulation. The processes of drying of composite pellets

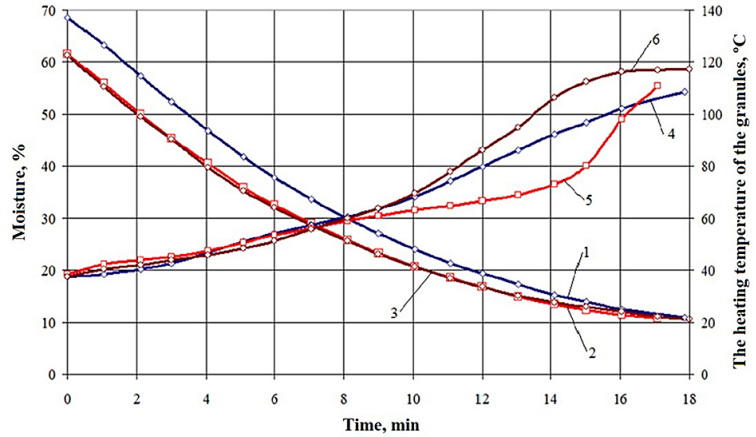

Figure 9. The effect of coolant temperature on the drying time of two- and threecomponent pellets at $t=120^{\circ} \mathrm{C}, V=2 \mathrm{~m} / \mathrm{s}$, $d=6 \mathrm{~mm}: 1,4-$ two-component pellets in the ratio of $50 \% \mathrm{~S}+50 \% \mathrm{P} ; 2,5$ - three-component pellets in the ratio of $45 \% \mathrm{~S}+45 \% \mathrm{P}+10 \%$ buckwheat husk; 3, 6-three-component pellets in the ratio of $45 \% \mathrm{~S}+45 \% \mathrm{P}+10 \%$ sawdust

on the basis of obsolete sludge, peat and biomass were investigated and effective drying modes were determined.

\section{REFERENCES}

1. DSTU 8727:2017. Osad stichnykh vod. Pidhotuvannia orhano-mineralnoi sumishi z osadu stichnykh vod. Derzhstandart Ukraine, Kyiv. (in Ukrainian).

2. DSTU EN 60584-1:2016. Peretvoriuvachi termoelektrychni. Chastyna 1. Tekhnichni kharakterystyky ta dopustymi vidkhyly elektrorushiinoi syly. Derzhstandart Ukraine, Kyiv. (in Ukrainian).

3. Du H., Li F. 2017 Characteristics of dissolved organic matter formed in aerobic and anaerobic digestion of excess activated sludge. Chemosphere. 2017, 168, 1022-1031.

4. Hvozdiak P.I. 2019. Biokhimiia vody. Biotekhnolohiia vody (autonography). Kyiv-Mohyla Academy Publishing House, Kyiv. (in Ukrainian).

5. Kelessidis A., Stasinakis A.S. 2012. Comparative study of the methods used for treatment and final disposal of sewage sludge in European countries. Waste Management, 32(6), 1186-1195.

6. Lykov A.V. 1968. Teoriya sushki (2th ed.). Energiya, Moskov.

7. Matsumiya Y. 2014. Green Energy Production from Municipal Sewage Sludge in Japan. Japan Sewage Works Association.

8. Mininni G., Blanch AR., Lucena F., Berselli S. 2014. EU policy on sewage sludge utilization and perspectives on new approaches of sludge management. Environmental Science and Pollution Research, 22(10), 7361-7374. https://doi.org/10.1007/ 
s11356-014-3132-0

9. Nezdoyminov V.I., ChernyishevaA.V. 2010. Migratsiya ionov tyazhelyih metallov pri ispolzovanii osadkov gorodskih stochnyih vod v kachestve udobreniya. Visnyk Donbaskoi natsionalnoi akademii budivnytstva i arkhitektury, 2(74), 150-157. (in Russian).

10. Petrova Zh., Novikova Yu. 2021, March 17. Preparation of raw materials, creation of compositions and granulation from obsolete sludge, peat and biomass. Ceramics: Science and Life, 1(50), 14-18. https:// doi.org/10.26909/csl.1.2021.2. (in Ukrainian).

11. Petrova Zh.A., Slobodyanyuk E.S. 2019. EnergyEfficient Modes of Drying of Colloidal CapillaryPorous Materials. J Eng Phys Thermophy 92, 1231$1238 \mathrm{https} / / / \mathrm{doi} .0 \mathrm{rg} / 10.1007 / \mathrm{s} 10891-019-02038-\mathrm{x}$

12. Sniezhkin Yu.F., Korinchuk D.M., Bezghin M.M., Stepchuk I.V. 2014. Enerhetychnyi analiz tekhnolohii vyrobnytstvatverdoho biopalyva. Scientific works, 3(45), 187-190. (in Ukrainian).
13. Suchkova N.G. 2007. Analiz sostoyaniya problemyi rekultivatsii ilovyih ploschadok ochistnyih sooruzheniy gorodov i perspektivyi dlya Harkovskogo regiona. The collection of reports of participants of the International Congress and Technical Exhibition ETEVK-2007, 279-284. (in Russian).

14. Tyagi V. K., Lo S.-L. 2013. Sludge: A waste or renewable source for energy and resources recovery? Renewable and Sustainable Energy Reviews, 25, 708-728. https://doi.org/10.1016/j.rser.2013.05.029

15. VermiTehnologii. Obezvrezhivanie osadkov stochnyih vod [Electronic resource] URL: http://www.greenpik.ru/sections/96.html \&article=17. (in Russian).

16. Zhen G., Lu X., Kato H., Zhao Y., Li, Y.-Y. 2017. Overview of pretreatment strategies for enhancing sewage sludge disintegration and subsequent anaerobic digestion: Current advances, full-scale application and future perspectives. Renewable and Sustainable Energy Reviews, 69, 559-577. https:// doi.org/10.1016/j.rser.2016.11.187 